\title{
Euphorbia smirnovii Geltman TÜRÜNÜN MORFOLOJİK VE KARYOLOJIK ÖZELLİKLERİ
}

\author{
İlker GENÇ ${ }^{1 *}$, Şükran KÜLTÜR ${ }^{1}$ \\ ${ }^{1}$ İstanbul Üniversitesi, Eczacılık Fakültesi, Farmasötik Botanik Anabilim Dalı. \\ *Corresponding author: e-mail: ilkgenc@istanbul.edu.tr
}

Alınış (Received): 26 Mayıs 2017, Kabul (Accepted): 18 Eylül 2017, Erken Görünüm (Online First): 13 Ekim 2017 ; Basım (Published): 15 Aralık 2017

\begin{abstract}
Özet: Bu çalışmada, ülkemizde Doğu Karadeniz ve Doğu Anadolu bölgelerinde doğal yayılış gösteren Euphorbia smirnovii Geltman türünün morfolojik ve karyolojik özellikleri incelenmiştir. Türün morfolojik betimi ayrıntılı olarak verilmiş ve fotoğraflarla desteklenmiştir. Ayrıca yaprak, kapsula ve tohum yüzey mikromorfolojileri SEM cihazı ile incelenmiştir. Bununla birlikte, Feulgen boyama tekniğiyle boyanan kök uçları, ezme preparat yöntemiyle preparat haline getirilerek karyolojik inceleme yapılmıştır. Böylece türün kromozom sayısı, karyotip formülü, ideogramı, kromozom ölçüm değerleri ilk kez bu çalışma ile tespit edilmiştir. Endemizm durumu şüpheli gösterilen türün Ermenistan'da da yayılış gösterdiği saptanmış ve türün endemik olmadığı netleşmiştir. Euphorbia smirnovii türünün yaprak alt ve üst yüzeyi ile kapsula yüzeyinin papiller ile kaplı olduğu görülmüştür. Elde edilen sonuçlara göre türün tetraploid olduğu ve kromozom sayıs1 $2 n=4 x=36$ olarak saptanmıştır. Türün karyotip formülü $32 \mathrm{~m}+4 \mathrm{sm}$ şeklindedir. En küçük kromozom boyu $0,79 \mu \mathrm{m}$, en büyük kromozom boyu $1,52 \mu \mathrm{m}$

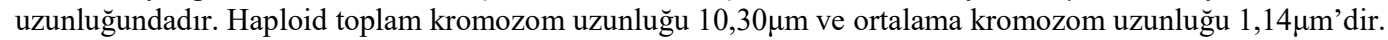

Anahtar kelimeler: Euphorbiaceae, sect. Pithyusa, kromozom, mikromorfoloji.

\section{Morphological and Caryological Features of Euphorbia smirnovii Geltman}

\begin{abstract}
In this study, the morphological and karyological characteristics of Euphorbia smirnovii Geltman, which is naturally distributed in Eastern Black Sea and Eastern Anatolia Regions, have been examined. The morphological description of the species is given in detail and supported by photographs. In addition, leaf, capsula and seed surface micromorphology have been investigated with SEM. Karyological investigation carried out by the standard Feulgen technique and squashes were prepared. The chromosome number, karyotype formula, ideogram, chromosome measurement values were reported for the first time in this study. It has been found that the species is also spreading in Armenia and it is clear that the species is not endemic. Euphorbia smirnovii, capsules, lower and upper surface of the leaf are covered with papilla. According to the results, the species was tetraploid with $2 \mathrm{n}=4 \mathrm{x}=36$ chromosomes. The karyotype formula is $32 \mathrm{~m}+4 \mathrm{sm}$. The smallest chromosome length is $0.79 \mu \mathrm{m}$ and the largest chromosome length is $1.52 \mu \mathrm{m}$. Haploid total chromosome length is $10.30 \mu \mathrm{m}$ and mean chromosome length is $1.14 \mu \mathrm{m}$.
\end{abstract}

Key words: Euphorbiaceae, sect. Pithyusa, chromosome, micromorphology.

\section{Giriş}

Euphorbia L. (Euphorbiaceae) cinsi dünya genelinde yaklaşık 1800 türü ile Angiospermler içinde en geniş 5 cinsten birisidir (Radcliffe-Smith 2001). Cins dünya genelinde kozmopolit bir yayılışa sahiptir. Başlıca yayılış alanları Güney Afrika, Doğu ve Kuzeydoğu Afrika, Kuzey ve Orta Meksika'nın yanı sıra Batı Asya'dır. (Govaerts ve ark. 2000). Cinsin yaşam formları tek yıllık bitkilerden, çalı ve ağaçlara kadar geniş bir yelpazeye sahiptir. Birçok türü ise kuru habitatlara uyum sağlamış sukkulent yapıdadırlar (Zimmermann ve ark. 2010). Euphorbiaceae familyası türleri birçok ülkede yerli halk tarafindan kanser, şeker hastalığı, ishal, kalp rahatsızlıkları, hepatit, sıtma romatizma gibi çok çeşitli hastalıklarda halk ilacı olarak kullanılmaktadır (Kumar ve Chaturvedi 2010). Euphorbia cinsinin kendi içindeki taksonomik sınıflandırması tür sayısının çok fazla olmasından dolayı oldukça zordur. Son yıllarda yapılan çalışmalar doğrultusunda cins 4 alt cinse ayrılmıştır. Bunlar altcins Rhizanthium; altcins Esula Pers.; altcins Euphorbia; altcins Chamaesyce Raf.'dir (Steinmann ve Porter 2002, Bruyns ve ark. 2006, Park ve Jansen 2007, Zimmermann ve ark. 2010).

Ağırlıklı olarak kuzey yarımkürenin ılıman bölgelerinde yayılış gösteren otsu ve çalımsı türler altcins Esula altında toplanmıştır. Bu altcins yaklaşık 400 türe sahiptir (Barres ve ark. 2011).

Türkiye'de Euphorbia cinsine ait 120 takson yayılış göstermektedir (Öztekin 2012, Yıldırımlı 2012, Genç ve Kültür 2016). 
Bu çalışmada, ülkemizde Doğu Karadeniz ve Doğu Anadolu bölgelerinde dar bir alanda doğal yayılış gösteren Euphorbia smirnovii Geltman türünün morfolojik ve karyolojik özellikleri incelenmiştir. Çalışmaya konu olan tür altcins Esula altında yer alan sect. Pithyusa (Raf.) Lázaro taksonomik gurubuna dâhildir. Türün morfolojik betimi ayrıntılı olarak verilmiş ve fotoğraflarla desteklenmiştir. Aynı zamanda kromozom sayısı, karyotip formülü, ideogramı, kromozom ölçüm değerleri ayrıntılı olarak sunulmuştur.

\section{Materyal ve Metot}

Tür ile ilgili gerekli literatür ve herbaryum çalışmaları yapıldıktan sonra çalışma materyalleri doğal yayılış alanlarından olgun meyveli döneminde toplanmıştır. Toplanan örnekler ve diğer herbaryum materyalleri ve türe ait literatürler dikkate alınarak türün deskripsiyonu yazılmıştır. Karyolojik çalışmalar için toplanan örneklerden olgun tohumlar ayrılmıştır. Daha sonra bu tohumlar petri kaplarında oda sıcaklığında çimlendirilmiştir. Oluşan kök uçları yaklaşık $1 \mathrm{~cm}$ uzunluğa ulaştığında ilk olarak $+4^{\circ} \mathrm{C}$ de 24 saat 8Hydroxyquinoline içinde bekletilmiştir. İkinci aşamada en az iki saat süreyle Carnoy çözeltisi (3:1; etanol: GAA) içinde tutulan kök uçları $1 \mathrm{~N} \mathrm{HCl}$ içinde $60^{\circ} \mathrm{C}$ de 12 dakika hidroliz edilmiştir. Hidroliz aşamasından sonra kök uçları Feulgen boyama tekniğiyle boyanmıştır. Boyanan kök uçları, ezme preparat yöntemiyle preparat haline getirilmiştir. Hazırlanan preparatlar mikroskop ve KAMERAM karyotip görüntüleme ve analiz sistemi yardımıyla incelenmiş, saptanan iyi dağılmış metafaz hücreleri fotoğraflanmıştır. Analiz için 5 adet iyi dağılmış metafaz evresi seçilmiştir. Son olarak 5 analizin ortalaması alınarak türün ideogramı oluşturulmuştur.

SEM analizi için geçmiş yıllarda yapılmış SEM çalışmaları incelenmiş ve bu çalışmaların ışığında gövde yaprağı, kapsula ve tohum üzerinde inceleme yapmaya karar verilmiştir. Çalışmada olgun bireylerin ilgili kısımları kullanılmıştır. Alınan bu materyaller ayrı ayrı stereo mikroskop altında incelenerek uygun olanlar iki tarafı yapıştırıcı özelliğe sahip karbon bandın bir yüzüne yapışması sağlanmış ardından diğer yüzü de metal taşıyıcı olan tablaya yapıştırılarak altın kaplama işlemine alınmıştır. Kaplama işleminin ardından materyaller FEI Quanta 450 FEG-EDS taramalı elektron mikroskobunda incelemeye alınarak fotoğrafları çekilmiştir. Taramalı elektron mikroskobu çalışması İstanbul Üniversitesi, Mühendislik Fakültesi, Kimya Mühendisliği laboratuvarında yapılmıştır.

\section{Sonuçlar}

Euphorbia smirnovii Geltman (Sin.: E. petrophila var. armena Boiss.)

Çok yıllık, taban kısmı odunsu olan otsu bitkilerdir. Gövde, toprak seviyesinden itibaren çok sayıda, en fazla 20 cm'ye kadar uzar.(Şekil 1a). Gövde yaprakları çok küçük papiller ile kaplı, şeritsi-oblanseolat, 0,5-2(-2,5)x(0,1-)0,3$0,6 \mathrm{~cm}$, ucu küt kenarları düz. Işın yaprakları yumurtamsıhemen hemen yuvarlak. Işıncık yaprakları hemen hemen küremsi-yumurtamsı baklavams1, 4-7 x 6-11mm, tepesi küt, mukrolu. Işınlar 3-5 adet, $2 \mathrm{~cm}$ ye kadar, en fazla bir kez dallanır veya dallanmaz. Yan ışınlar 0-3 adet. Glandlar böbreksi veya çok kısa boynuzlu (Şekil 1b). Kapsula yumurtamsı, 2,5-3mm çapında, yüzeyi minik papilli. Tohum basık genişçe dikdörtgensi, 2,3-2,8mm boyunda, 1,6-1,9mm eninde, düzensiz hafif çukurlu, gri-açık kahve renkli. Karunkula tepede, konik şekilli tohumun yaklaşık 1/3 boyunda, sarı renkli (Şekil 1c).

Çiçeklenme dönemi Mayıs-Ağustos ayları arasında olmaktadır. Kalkerli, taşlı açık yamaçlarda yayılış gösterir. Ülkemizde Gümüşhane ve Erzincan'da doğal yayılış gösteren takson Erivan (Ermenistan)'dan da kaydı bulunduğu için endemik statüsünü kaybetmiştir (Geltman 1996).

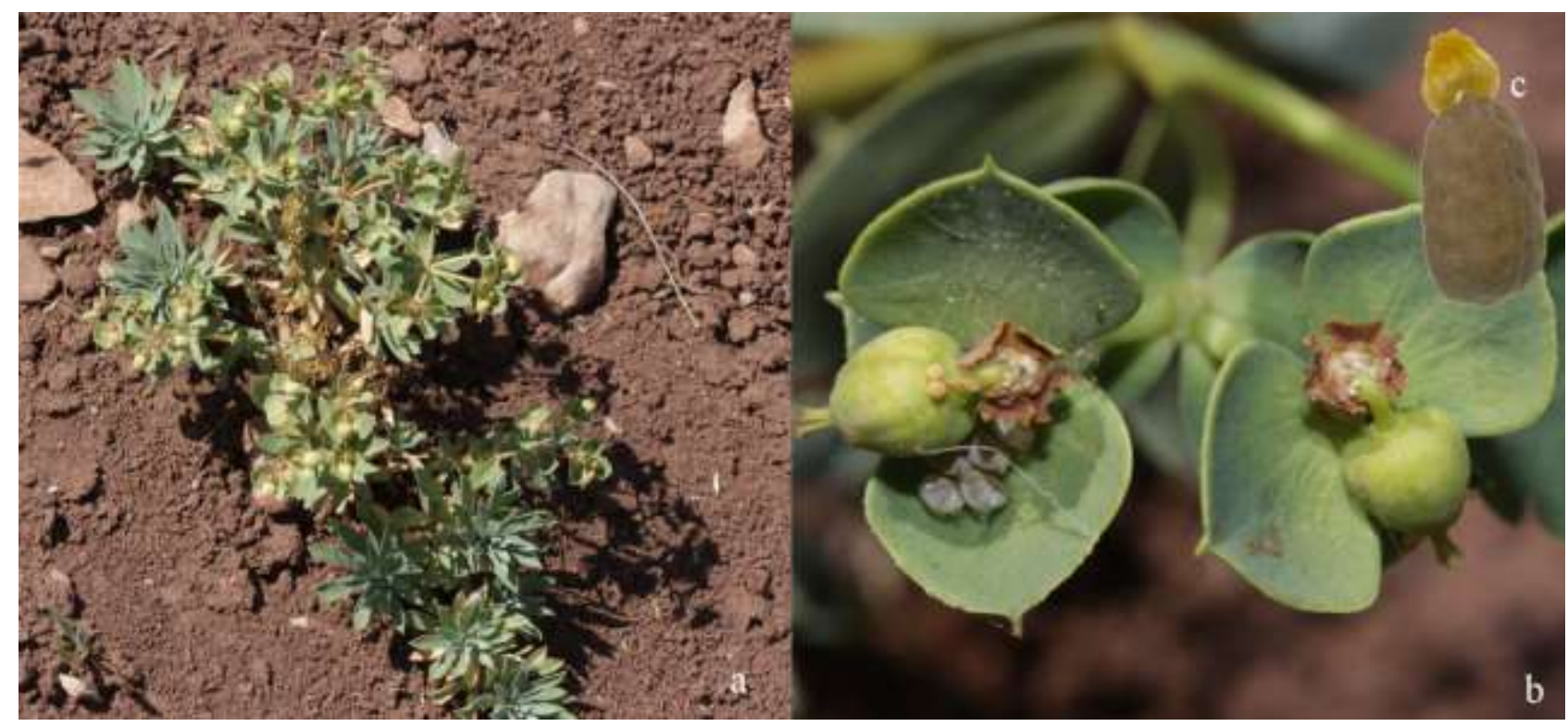

Şekil 1. E. smirnovii a. genel görünüş, b. kapsula ve gland c. tohum. 


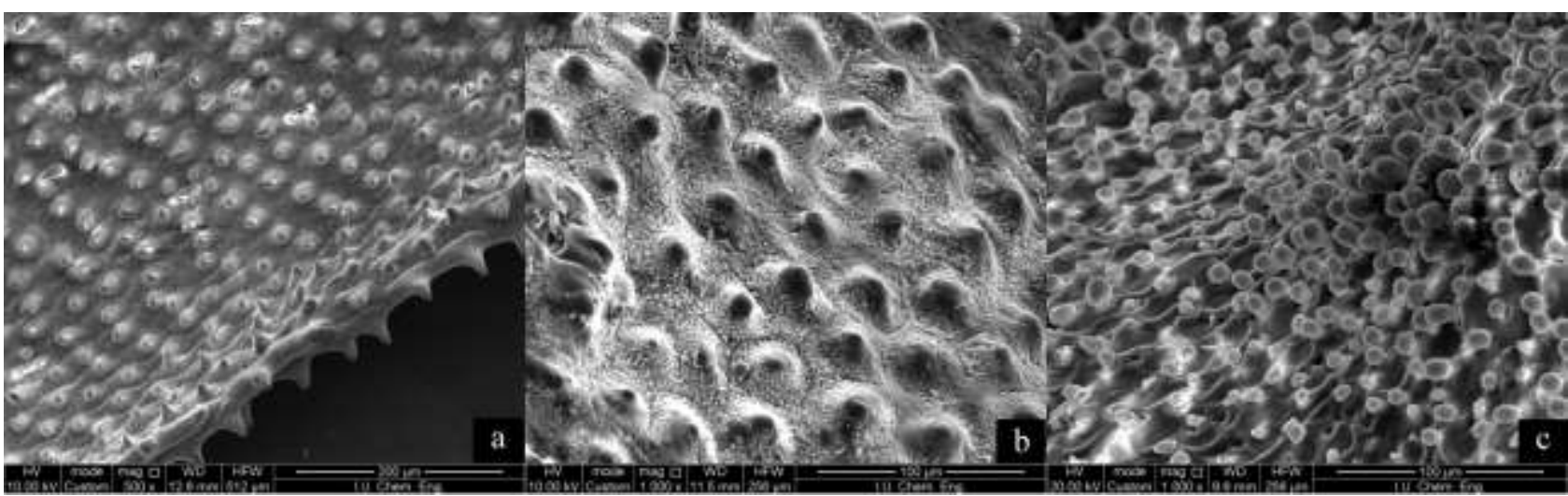

Şekil 2. E. smirnovii a. yaprak yüzeyi, b. kapsula yüzeyi, c. tohum yüzeyi.

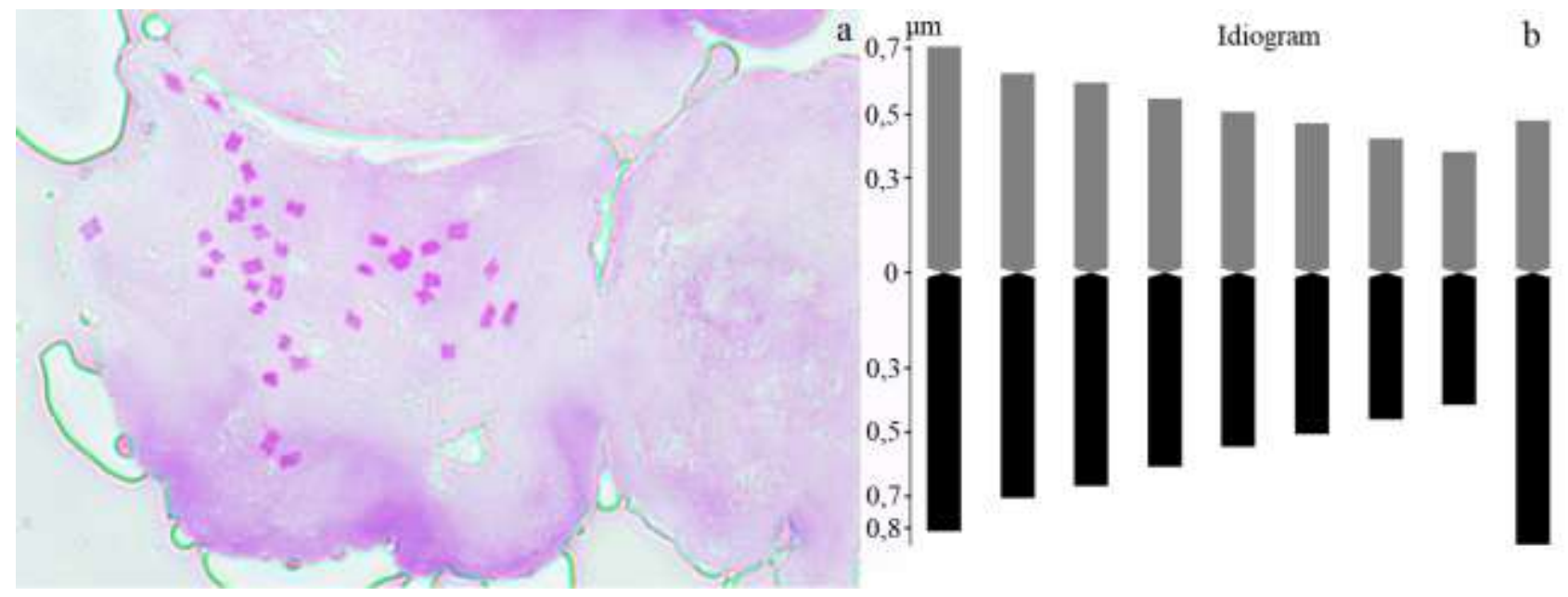

Şekil 3. E. smirnovii a. metafaz kromozomları b. ideogram.

İncelenen Örnekler: Bayburt, in Rupibus pr. Baibout (Bayburt) Armeniae, 20.06.1862, Bourgeau 242 (isotype) (K, foto !). Erzincan, Üzümlünün üstleri, taşlık yamaçlar, 25.07.2015, İ. Genç 2468, A. Kandemir.

Yapılan SEM analizleri sonucunda türün yaprak alt ve üst yüzeyi ile kapsula yüzeyinin papiller ile kaplı olduğu görülmüştür (Şekil 2a ve b). Tohum yüzeyinin ayrıntılı incelenmesi sonucunda da testa hücrelerinin daireseluzamış (rounded-elongate) şekilli, hücre duvarlarının yüzeye göre genelde yüksek olduğu, hücre yüzeylerinin de düzensiz çukurlu olduğu görülmüştür. (Şekil 2c).

Euphorbia smirnovii türünün karyolojik incelemeleri sonucunda türün tetraploid kromozom sayısına sahip olduğu saptanmıştır. Buna göre kromozom sayıs1 $2 n=4 x=36$ olarak sayılmıştır (Şekil 3a). Türün karyotip formülü $32 \mathrm{~m}+4 \mathrm{sm}$ şeklindedir. En küçük kromozom boyu $0,79 \mu \mathrm{m}$, en büyük kromozom boyu $1,52 \mu \mathrm{m}$ uzunluğundadır. Haploid toplam kromozom uzunluğu $10,30 \mu \mathrm{m}$ ve ortalama kromozom uzunluğu $1,14 \mu \mathrm{m}$ 'dir (Şekil 3b).

\section{Tartışma}

Bu çalışmada, ülkemizde Doğu Karadeniz ve Doğu Anadolu bölgelerinde doğal yayılış gösteren Euphorbia smirnovii Geltman türünün morfolojik ve karyolojik özellikleri incelenmiştir. Yapılan literatür incelemeleri sonucunda Türkiye Bitkileri Listesi adlı eserde Öztekin (2012) tarafindan endemizm durumu şüpheli gösterilen türün Ermenistan'da da yayılış gösterdiği saptanmış ve türün endemik olmadığı netleşmiştir.

Euphorbia smirnovii türünün yaprak alt ve üst yüzeyi ile kapsula yüzeyinin papiller ile kaplı olduğu görülmüştür. $\mathrm{Bu}$ morfolojik özellik Salmaki ve ark. (2011) tarafından yapılan çalışmada yer alan sect. Pithyusa (subsect. Conicocarpae Porkh.) türlerinin çoğunda görülmektedir.

Euphorbia smirnovii türünün, kromozom sayıs1, karyotip formülü, ideogramı, kromozom ölçüm değerleri ilk kez bu çalışma ile tespit edilmiştir.

\section{Teșekkür}

Bu çalışma TÜBİTAK tarafindan 114Z125 numaralı proje ile desteklenmiş̧ir.

$\mathrm{Bu}$ çalışmanın özeti poster bildiri olarak, XXII. Bitkisel İlaç Hammaddeleri Toplantısında (31 Ağustos-5 Eylül 2016, Trabzon) (özet kitabı sayfa 129) sunulmuştur. 


\section{Kaynaklar}

1. Barres, L., Vilatersana, R., Molero, J., Susanna, A. \& Galbany-Casals, M. 2011. Molecular phylogeny of Euphorbia subg. Esula sect. Aphyllis (Euphorbiaceae) inferred from nrDNA and cpDNA markers with biogeographic insights. Taxon, 60: 705-720.

2. Bruyns, P.V., Mapaya, R.J. \& Hedderson, T. 2006. A new subgeneric classification for Euphorbia (Euphorbiaceae) in southern Africa based on ITS and $p s b A$-trnH sequence data. Taxon, 55: 397-420.

3. Geltman, D. 1996. New data on distribution of Euphorbia (Euphorbiaceae) species in the Caucasus. Botanicheski Zhurnal, 81(11): 100-103.

4. Genç, İ. \& Kültür, Ş. 2016. Euphorbia akmanii (Euphorbiaceae), a new species from Turkey. Phytotaxa, 265(2): 112-120.

5. Govaerts, R., Frodin., D. \& Radcliffe-Smith, A. 2000. World Checklist and Bibliography of Euphorbiaceae (with Pandaceae) 2. Kew, Royal Botanic Gardens.

6. Kumar, G.P. \& Chaturvedi A. 2010. Ethnobotanical observations of Euphorbiaceae species from Vidarbha region, Maharashtra, India. Ethnobotanical Leaflets, 2010(6): 4.

7. Öztekin, M. 2012. Euphorbia, 414-424 s. In: (Editörler). Güner, A., Aslan, S., Ekim, T., Vural, M. \& Babaç, M.T. Türkiye Bitkileri Listesi (Damarl Bitkiler). Nezahat
Gökyiğit Botanik Bahçesi ve Flora Araştırmaları Derneği Yayını, İstanbul, xx1 + $1290 \mathrm{~s}$.

8. Park, K.R. \& Jansen, R.K. 2007. A phylogeny of Euphorbieae subtribe Euphorbiinae (Euphorbiaceae) based on molecular data. Journal of Plant Biology, 50: 644-649.

9. Radcliffe-Smith, A. 2001. Genera Euphorbiacearum. RBG, Kew, UK. X + 455 pp.

10. Salmaki, Y., Zarre, S., Esser, H.J. \& Heubl, G. 2011. Seed and gland morphology in Euphorbia (Euphorbiaceae) with focus on their systematic and phylogenetic importance, a case study in Iranian highlands. Flora-Morphology, Distribution, Functional Ecology of Plants, 206(11): 957973.

11. Steinmann, V.W. \& Porter, J.M. 2002. Phylogenetic relationships in Euphorbieae (Euphorbiaceae) based on ITS and ndhF sequence data. Annals of Missouri Botanical Garden, 89: 453-490.

12. Yildırımlı, Ş. 2012. The heaven of gypsophilous phytodiversity of Turkey: Kepen, Sivrihisar, Eskişehir, Turkey, 13 taxa as new. OT Sistematik Botanik Dergisi, 19(2): 1-51.

13. Zimmermann, N.F.A., Ritz, C.M. \& Hellwig, F.H. 2010. Further support for the phylogenetic relationships within Euphorbia L. (Euphorbiaceae) from nrITS and trnL-trnF IGS sequence data. Plant Systematics and Evolution, 286: 39-58. 
